African women's control over their sexuality in an era of AIDS

\author{
I.O. Orubuloye, Pat Caldwell and John C. Caldwell
}

Health Transition Working Paper No. 12, 1992 


\title{
African women's control over their sexuality in an era of AIDS
}

\author{
I.O. Orubuloye, Pat Caldwell and John C. Caldwell
}

The degree to which sub-Saharan African women can control or modify their sexual relations with their partners, especially with husbands, has hovered in the background of family planning research but has now assumed centrality with regard to AIDS. Given the relatively high incidence of the other sexually transmitted diseases in the region before the HIV/AIDS epidemic, it is surprising that the issue was not explored in terms of these infections, but the research record in this regard is almost bare. Even in terms of AIDS, it is only in its infancy.

The fact that no one investigated women's control over their sexuality, outside the circumstances where sexual abstinence was mandated, is probably explained by the assumption that they had no such control. A committee of Yoruba, the people of southwest Nigeria who form the main focus of this paper, concluded during the first decade of the present century in a report to the British Government that 'The husband has rights to his wife's person but none to her property' (Hopkins, 1969:81). Caldwell and Caldwell claimed, when discussing family planning, that husbands had more absolute rights over their wives' reproduction than over their sexuality, but, in the latter regard, they were referring to relations with others rather than with the husbands themselves (Caldwell and Caldwell, 1987:420-421).

The AIDS epidemic has made an understanding of the issues involved a matter of urgency, and attempts have been made to approach them even employing large-scale data sets (Cleland et al., 1991). Drawing on East African research in Kampala, Uganda, Ankrah (1991) reported that women spoke of their vulnerability; among the areas where they lacked any control

were the lack of decision-making powers in matters of sex, their susceptibility to infection from husbands to whom traditions permit multiple partners, the necessity to use sex as an economic resource [with husbands as well as others], and a sense of helplessness because of ignorance of ways to change their social situation (Ankrah, 1991:971).

She also quoted the conclusion of the First International Workshop on Women and AIDS in Africa, held in Zimbabwe, that 'women have limited power to negotiate or enforce strategies to reduce their risk of HIV infection'. Ankrah saw this situation as arising from 'The low status of the African woman...'.

The rural woman in particular in Africa may find herself economically dependent on her husband, but without any leverage at all, such as independent income. Lacking the right of ownership, control over, or adequate access to land and cash, the rural African woman is highly disadvantaged... (Ankrah, 1991:971).

Husbands who have gone to the towns, often setting up new households and having multiple sexual liaisons, 'can still demand their matrimonial sexual rights whenever they return to the household'. This extreme material powerlessness does not explain relative female sexual 
disadvantage among the Yoruba or in much of coastal West Africa, a theme to which we shall return.

Very little attention has been paid to what actually happens within a family when sexually transmitted disease breaks out. There is really nothing recorded on the older venereal diseases, and little on AIDS. Ankrah (1991:971) reports that in Kampala, 'When a woman falls ill or shows AIDS related symptoms before her partner does, she is more likely than he to be sent back to her relatives or to be abandoned'. A major continuing research program among the Baganda of Uganda, which began in 1987, reported that, because of the AIDS epidemic, some women are limiting the numbers of their extramarital partners, but none feel that they can in any way modify their sexual relations with their husbands or insist on the use of condoms even when they are deeply apprehensive about what might result from the husbands' promiscuous sexual relations with a range of other women (McGrath et al., n.d.:18-24).

Many of the questions which we address in this paper with regard to other sexually transmitted diseases were raised in terms of HIV/AIDS by Irwin and colleagues (1991) in focus group research in a large factory in Zaire, where discussions were held with 78 male factory workers and 48 of their wives. This group were urban and reasonably well educated. Just over half the men said that if they found they were HIV positive, they would not want their wives to know, but most added that they would take precautions. In contrast, the majority of women said that if it happened to them, they would tell their husbands, apparently partly because men have greater sexual rights over women than women have over men, but partly also because they had no other way of getting the money necessary for treatment. In terms of sexuality, most women said they would stay with a seropositive husband to care for him but would refuse to have sex with him or share the same bed. Minorities believed that they would stay and have sex when condoms were used, or would separate or divorce, usually under pressure from relatives to remain healthy and, above all, to bear healthy children by another man. A few wives said that it was inevitable that they would stay and continue sexual relations as before. Half of all husbands said that separation would follow the discovery that they were seropositive, most believing that wives would take the initiative in this. Most of the rest said that they would stay together without sex (some adding the qualification 'until they were cured'), while a few reported that they would continue to have sex either with condoms or until the AIDS symptoms developed. When it was the wife who was found to be seropositive, most said they would wish to continue to live with their husbands but without sexual relations, while the rest said that divorce was inevitable even if it was probable that their husbands had infected them. This suspicion was confirmed by the men, a large majority of whom believed divorce would follow with accusations of infidelity. Both men and women agreed that their families would play roles, his family normally being supportive and usually demanding a divorce (and accusing the wife of being the source of infection), and her family being less likely to be supportive and less likely to demand divorce. The majority of respondents did not believe that, even if the disease did strike, condoms would be used in their relationship, even though most knew where to obtain them. The sequelae of AIDS are much more likely to be sexual abstinence, with or without separation, than the employment of condoms. Apart from fear of and aversion to condoms, and the difficulty of discussing their use in marriage even when HIV/AIDS provides evidence of relations with other persons, most of the 
women did not believe that condoms would succeed in protecting them from infection (although the men were somewhat more optimistic). All these responses should be interpreted in the light of the fact that 40 per cent of the males and 21 per cent of the females believed AIDS to be curable, and that 12 per cent of each sex had already used condoms.

Thus, speculation on what is likely to happen to marital relationships and other partnerships as a result of the infection of either partner was becoming common, but was supported by little testimony as to what actually did happen. Wives seemed relatively defenceless, but most of the evidence came from East Africa, especially Uganda. Women's ability to defend themselves against HIV infection was likely to have antecedents in their ability to defend themselves against the older sexually transmitted diseases, but nothing was known on this subject.

In these circumstances, two related programs planned research on women's control of their sexuality (see Acknowledgements for details of the programs): in southwest Nigeria, in the presence of STDs, and in southern Ghana, in the presence of HIV/AIDS. This division was dictated by the higher levels of the latter disease in Ghana. The Nigerian study is reported here.

\section{The Ekiti Project}

The collaborative OSUA-ANU research program in the Ekiti District of Ondo State had worked since 1989 in interrelated areas of health, STDs, HIV/AIDS and fertility. Ekiti is the northernmost district of Ondo State, about 150 miles in a direct line, and 200 miles by road, northeast of Lagos (Orubuloye, Caldwell and Caldwell, 1991; Caldwell, Orubuloye and Caldwell, 1991). It is also the northeast corner of the area settled by the Yoruba people. The district headquarters is Ado-Ekiti, an old centre which now has a population of around 150,000 persons. STDs of various types have long been common, although most of the population identify all sexually transmitted disease as gonorrhoea.

In terms of women's control over their sexuality, it is important to note that the culture has long expected women to shoulder the responsibility for ensuring that no sexual relations take place, no matter how importuning husbands or other partners may be, during menstruation and the postpartum period, and after becoming a grandmother or reaching menopause. These periods totalled over 60 per cent of a woman's time between menarche and menopause in a study of Ibadan city as late as 1973 (Caldwell and Caldwell, 1977). Although the main responsibility is on the woman to maintain these periods, she is helped by the societal consensus that they are proper and necessary and that ignoring the postpartum proscription on sexuality may result in the death of children; and by the overseeing of the period and even physical intervention by relatives (P. Caldwell and J.C. Caldwell, 1981).

Yoruba society, like that of most of coastal West Africa, differs from the descriptions of East Africa with regard to women's general powerlessness and to the explanations for limited control of their sexuality. Yoruba women monopolize trading and have rights to much of those farm products they help to produce. They almost always have separate budgets from their husbands, and largely support themselves and their children. They can easily get a divorce and have a right to return to their families of origin. 
Yet neither traditional control of mandated abstinence periods, nor a very substantial degree of economic and physical independence, seems to guarantee them as much control over their sexuality as might be anticipated. The reasons are the same as those explaining why such relatively independent women lack much control over their practice of contraception. The patrilineal nature of the society and the payment of bridewealth, even though now usually small and little more than symbolic, gives a husband the right to demand both sex and reproduction (Caldwell and Caldwell, 1987:420-421). A woman who refuses sex for any period, without a very good reason, must anticipate a breakdown in the marriage, and hence must take that into account when making sexual decisions. It was discovered in Ibadan that the situation was not very different in terms of single girls. Their boyfriends insisted that a refusal of sex showed the lack of a real relationship, in a situation where most girls felt the need of friendship and stable relationships and were terrified of precipitating a crisis (P. Caldwell and J.C. Caldwell, 1987).

Ado-Ekiti was in 1991 a suitable place for this research. Levels of gonorrhoea in southern Nigeria were probably around 10 per cent a decade ago and appear still to be around that level in Ekiti (Osoba, 1981; Orubuloye et al., 1991). From 1989 the Nigerian Population Policy ensured that condoms were freely available and they are now stocked by all family planning centres and most pharmacies and medical stores (Cald well, Orubuloye and Caldwell, 1992).

The study was carried out in late 1991 and consisted of a probability sample of 600 women drawn from Ado-Ekiti and of in-depth interviews with a subsample of those identified by a battery of questions as having known that their sexual partners were suffering from a sexually transmitted disease, or having themselves suffered from such a disease. Our interest lay both in what rights women had to refuse or modify sexual relations in the first circumstance and whether there was a symmetry in the situation of spouses relative to each other in the two situations. By marital status, 8 per cent of the women were single, 83 per cent currently married, 3 per cent divorced or separated, and 5 per cent were widows. Half of the married women were in polygynous relationships.

Over 99 per cent of the women interviewed knew something about sexually transmitted diseases and how the infection was passed on. Most were apprehensive and most felt that their male partners' sexual activities left them exposed to the possibility of infection. However, most of their knowledge and apprehension was in relation to gonorrhoea. There was surprisingly little knowledge of other STDs, although there was a growing realization that AIDS might be on its way.

Of the total respondents, 49 ( 8.2 per cent) of the women reported having had partners who had suffered from sexually transmitted diseases and 48 ( 8.0 per cent) reported that they had themselves experienced STDs while in some relationship. The similarity in numbers here strikingly resembles the situation reported elsewhere with regard to HIV/AIDS. Fewer women than men have multiple sexual partners, but the fact is that a higher proportion of them are infected by permanent partners. However, only a small number of these cases report the reactions of spouses to each other when both were infected during the one episode.

We report first on the attitudes and experience of all respondents in refusing sex to partners - usually temporarily; we then specifically examine the experience when one partner or the other had been identified as suffering from a sexually transmitted disease. 


\section{A woman's right to refuse to have sex with a partner}

Certainly Yoruba women have always had the right to refuse sex with partners on certain occasions. Indeed, in a range of circumstances it was morally obligatory. There was pressure of varying degrees on women to refuse sex before marriage, especially if they were betrothed; while menstruating; during pregnancy, especially in the later months; for up to three years after childbirth, especially while breastfeeding; after becoming a grandmother; and certainly after menopause. These were, admittedly, special (although frequent) occasions, and the proscription did not apply at other times. Nevertheless, the role that such occasions played, and the authority it gave to women with regard to sexual relations, mean that the concept of the female right to refuse a partner sexual relations is central to the culture, and may, especially with social change, be transferable to other circumstances.

Thus, when the respondents were asked whether a woman had the right to refuse her partner sex, 94 per cent of them immediately asserted that she certainly had this right; and 97 per cent of them stated that it was a fundamental female or human right or gave examples of when the right should be exercised.

Table 1.

Reasons given by respondents who had refused their partners sexual relations $(\mathrm{N}=580)$

$\begin{array}{lll} & \text { Response } & \\ \text { Major category } & \text { Subcategory }\end{array}$

(1) Forbidden time:

(a) menstruation 10

(b) postpartum sexual abstinence

(c) too soon after birth for sex without 10 contraception

(2) Antagonism:

(a) punishment for his behaviour

(b) punishment (or decision not to have sex) when 2 husband has taken another wife

(c) fight

(d) unhappy (usually with the husband or the marriage)

(e) husband drunk

(3) Not inclined:

(a) tired or sick

(b) too much sex

(c) the wife also has a right of choice

2

$56 \%$ $100 \%$

The respondents were then asked whether they had ever refused a demand by their partner for sex. Most assumed that the cessation of postpartum and similar periods of sexual abstinence was decided by discussion and rarely reached the point of a demand. Nevertheless, 77 per cent of respondents reported that they do refuse sex to their partners, and 97 per cent described at least one occasion as is summarized in Table 1. Most gave multiple responses and 
hence it is the distribution of responses which is presented. However, most took the traditional forbidden times for granted and concentrated on circumstances where women could exercise a choice.

Postpartum sexual abstinence is increasingly being partly replaced by contraception. In these circumstances one might anticipate that a growing number of women would forbid sex soon after a birth on the grounds that one or other of them had forgotten the contraception.

Sections (2) and (3) of Table 1 are somewhat artificially divided, the division depending on the respondent's reaction to events rather than on the underlying problems themselves. The punishments, the fights, the unhappiness, even the tiredness and many of the occasions when a wife insists that she too had a choice arose far more often than not from the husband's outside social life and from his relationships or suspected relationships with other women. To a large extent they were a product of a polygynous society where de facto polygyny extends far beyond the boundaries of formal polygyny. The society has traditionally insisted that women cannot put their complains on these matters into words, and many still feel they have no alternative to stating that they feel tired, which is often true enough, partly for emotional reasons. Many feel that their husbands have, before the occasion recorded here, shown little interest in them, evidence of other women and perhaps of their own advancing age.

The interviewers continued to focus on this occasion, and on the husbands' reactions. As interpreted by the respondents, these reactions are summarized in Table 2.

Table 2

Reported immediate reactions of male partners to the respondents refusing them sexual relations $(\mathrm{N}=580)$

$\begin{array}{lll}\text { Major category } & \text { Response } & \text { Subcategory }\end{array}$

Percentage of all responses

Hostile:

Tried to have sex by force

Furious, angry, annoyed

Offended

Silent, would not speak

Pleaded for her to change her mind

Reported this to her parents, threatened to send

her away

Turned to other wife

Went out to other women

Did not sexually approach her again

Accepted the refusal: Understood why she refused

Apologized for improper approach

Accepted situation calmly
$42 \%$

1
21
8
5
6
1

21

8

5

1

$5 \%$

3

4

1

27

Cannot remember, cannot describe, no response 
Male partners were, more often than not, angry. However, rape within marriage is not common. The society is not domestically violent, and the safety valve is that most men can turn to other women. This is also uppermost in the minds of many of the wives or women friends. Few wives put this into words. They are not supposed to, as was made clear in a 1974-5 study of Ibadan (P. Caldwell and J.C. Caldwell, 1981:86-88). In a 1991 study of Ondo Town only 10 per cent of philandering husbands seriously reported that their wives knew of their other relationships (Orubuloye et al., 1992). This is the central pretence of the society and makes large-scale sexual networking possible. That networking is based on the fact that the society is in spirit even more polygynous than it is formally, and it is this that restrains women from refusing sex to their partners too often. These fears are brought out clearly in Table 3 where the responses are set out to the more general question 'What happens if a woman refuses sex to her partner?'. Here the answers were not only generalized but were more in terms of the longer-term reaction.

The divisions in Table 3 are less a categorization of the personalities and philosophies of husbands than of the types of offence committed. As we will see, diagnosed STD infection in male partners tends most often to fall into the category of being understood by their partners, especially if it is believed that the cure will take little time.

Table 3.

Responses to the question "What happens if a woman refuses sex to her partner?" $(\mathrm{N}=601)$

\begin{tabular}{|c|c|c|c|}
\hline Major category & Subcategory & \multicolumn{2}{|c|}{ Percentage of all responses } \\
\hline \multirow{7}{*}{ Negative reactions: } & Turns to other wives & 1 & \\
\hline & Looks for other wives & 6 & \\
\hline & Turns to other women & 9 & \\
\hline & Leads to separation or divorce & 9 & \\
\hline & Wife no longer receives any support & 4 & \\
\hline & Unhappiness in the home & 31 & \\
\hline & Husband believes wife has lover & 1 & $61 \%$ \\
\hline Neutral reactions: & Partner usually understands & 8 & \\
\hline & Partner ignores the situation & 28 & $36 \%$ \\
\hline No response & & & $\begin{array}{r}3 \% \\
100 \%\end{array}$ \\
\hline
\end{tabular}

Clearly, much refusal or prolonged refusal of sex is dangerous. Nevertheless, as a woman becomes older, and as the husband acquires more women friends or wives, both wife and husband may accept her refusal to continue having sexual relations. Indeed, he, or both, may desire it.

Nevertheless, the chief constraint on wives refusing sex, except where the society holds them to be in the moral right in such circumstances as in the menstruation and postpartum periods, is the ease with which husbands can seek sexual solace elsewhere. Temporary refusal 
of sex may easily become permanent, or it may lead to the breakup of the household, or to the appearance of more wives. We asked wives about the social and cultural pressure on them to accede to husbands' demands and nearly all said such pressures were, and, as far as they knew, always had been non-existent. Certainly, in traditional rural society, a wife who refused sex to her husband would face not only pressure from him but from his relatives and ultimately their own. But these urban wives do not appear to face such pressures and most do not appreciate that they ever existed. The pressure on these modern urban wives was the need to take the conjugal consequences into account. The wives are not even very afraid of violence, again because the husband has so many other options.

This, then, is the context within which we must endeavour to understand what happened in those relationships where STDs struck and what might happen as HIV/AIDS spreads.

\section{Women whose current partners had contracted STDs}

Although most of the 49 women who reported having had infected partners were married, single women were significantly more likely to have gone through this experience. This appears to be explained by the fact that the single group contained a proportion of young women who put off their marriages longer than most and had a succession of partners before marriage. The most significant differential (both statistically and socially) was that between women with a single partner and those in polygynous marriages. Over one-third of the women were currently. polygynously married, but this group provided only one-seventh of the number with partners who had suffered from STDs. This is further confirmation of the direct observation that polygynously married men have fewer outside liaisons than those men with a single partner (Orubuloye et al., 1991:70).

Gonorrhoea was identified as the STD by $46(94 \%)$ of the respondents and syphilis by only 2 (4\%). Clearly other less easily identified STDs are underreported but these figures bring out clearly why the population draws little distinction between venereal disease and gonorrhoea.

Most of the population do not easily recognize the symptoms of STDs. Table 4 shows how the respondents realized that their partners were infected.

Table 4.

How women learnt that their partners were infected with an STD

$\mathbf{N}$

\begin{tabular}{rr}
34 & 70 \\
4 & 8 \\
7 & 14 \\
3 & 6 \\
1 & 2 \\
\hline 49 & 100 \\
\hline
\end{tabular}

Told by partner

Told by doctor after partner had infected respondent

Told by co-wife or other partner of partner after she had been infected by him

Suspected from partner's symptoms

No response

One reason that STDs are so dangerous and spread so widely is that so few people quickly recognize the symptoms. Women often fail to recognize the disease in themselves because vaginal infections and discharge are common. They may fail to recognize symptoms in their 
husbands because to a very considerable extent they live separate lives with sexual intimacy only at night, and often know little about where and when husbands urinate. Ultimately, the source of knowledge is the health system, both modern and traditional. Men told their wives or other female partners because doctors had diagnosed the complaint and insisted that a cure could be effected only by treating both partners. Similarly doctors told the women themselves or infected co-wives.

Table 5 presents the respondents' sexual reactions on learning of the infection.

Table 5.

Women's sexual reactions to the knowledge of their partners' infection

N $\quad \%$

Continued normal unprotected sexual activity

Continued sexual activity but with condoms - suggested by husband - insistence of wife

Refused sex until partner underwent treatment No response

\begin{tabular}{rr}
2 & 4 \\
4 & 8 \\
4 & 8 \\
37 & 76 \\
2 & 4 \\
\hline 49 & 100 \\
\hline
\end{tabular}

The table brings out clearly the situation described at greater length by many of the respondents. All the single women refused sex, and this is a freedom that everyone understands they have. What is more striking is that most wives were also in a position to do so. They can exercise this right because of the leverage they possess from the instability of Yoruba marriages, from the fact that nearly all earn incomes, and because they and their children will be received back by their families of origin. They can also exercise it because they have a traditional duty to refuse sex at times of impurity or disability such as during menses or in the postpartum condition and it is easily accepted by partners and by the community that STDs can be classified in this way. What is particularly interesting in what may be an early AIDS epidemic is that 16 per cent of couples employed condoms. This has proved possible because a similar proportion of Ado-Ekiti's couples are now using condoms for fertility control (Caldwell et al., 1992). However, the two groups are not identical, for some women who trust condoms to achieve fertility control do not have the same faith with regard to their imperviousness to infection, while others, who normally find condoms distasteful, will agree to their use as a protection against infection. Another question remains lurking in these responses, which we cannot answer because we did not interview the male partners. The usual male response to the postpartum sexual abstinence of wives is to go to other women. Did these men with identified STDs do this without revealing their infection or did they too regard themselves as hors de combat during this period?

None of the marriages broke up as a result of the disease. One reason was that all the partners agreed to treatment, an unsurprising situation in view of the fact that nearly all knew the exact nature of the complaint because they had sought medical help for their physical disorders. 
Another reason is that most Yoruba women take it for granted, often reluctantly, that their partners have other partners. Interestingly, STDs are associated with sexual networking rather than specifically going to prostitutes, an accusation that has frequently been made in the West. Only four women (8\%) mentioned prostitutes or bar girls as the likely source of infection, further evidence of a diffused rather than focused pattern of sexual relations (Orubuloye et al., 1992). However, it is noteworthy that $34(69 \%)$ of the women employed derogatory phrases (some equivalent to the contemporary English 'cheating') when referring to the behaviour that had resulted in infection.

An important question is whether women prefer to maintain secrecy about these problems of their conjugal relationship or whether they need social and emotional support. Only onethird of the respondents discussed the problem with anyone other than their partner or health personnel. This would appear to provide solid evidence that most were quite clear about their right to adopt the courses they did, and indeed that their husbands usually accepted the situation. Of those who did tell others, half told their parents, seeking a traditional form of support, half told their women friends, seeking a more contemporary form of solidarity, and a few felt it their duty to warn co-wives.

\section{How male partners behave toward women who have contracted STDs}

Of the 48 women who knew that they had contracted an STD, almost all gonorrhoea, exactly half told their partners while the other half did not. Clearly, disclosure failures on this scale limit the capacity of partners to take action. Those who told their partners usually did so because they believed that their partners were the source of infection and wished to allocate blame and share responsibility for doing something about it. In nearly all cases their doctors had told them that both would have to be treated. We do not know how many men failed to tell their female partners, but we believe it was a lower proportion and evidence that husbands are less afraid of wives than wives of husbands, at least in these circumstances, because a polygynous society is much more likely to condone men having multiple partners.

In these 24 relationships where the women had revealed the disease, 17 of the male partners refused any more sexual relations until the woman was cured. Most of the rest were not so much brave or chivalrous as convinced that they had the disease themselves and had brought it into the relationship. Most went for treatment at the same time as their wives or girlfriends. Of the 24 male partners, only one demanded a divorce, four more were angry, while another gave his wife long lectures. Three said or did nothing. But the rest confined themselves to practical steps, arranging treatment or advising on it. The reaction among the 17 women who were refused sex until cure by their partners was agreement by 11, and sadness and insecurity in three more cases. Two women pleaded for continued sexual relations and a third woman went off to another man. One of the 24 infected women reported feeling ashamed that she had contracted the disease, more felt angry or uncomfortable, and most just regarded it as one of life's vicissitudes. Nevertheless, they did not readily discuss it: only one-third of them told anyone except those treating them and their partners, and of these half informed a relative and half a friend, often seeking advice about what to do. Of those who told their partners, only four 
believed he had told anyone except healers, and only one of these that he had informed his own relatives.

There is less difference between the situations according to whether the female or the male is infected than we had anticipated. No infected husbands lost their wives and only one infected woman lost her husband. It is a tolerant society, especially on sexual matters, and venereal infection is often regarded as bad luck. Part of the husbands' tolerance arises from the fact that many suspected that they had infected their wives. We were startled at first to learn that, while 76 per cent of women had refused sex until treatment to infected husbands, only 35 per cent of husbands refused sex to infected wives. It turned out that this was not so much a measure of women's liberation or of less fear of gonorrhoea among men - although that undoubtedly is the situation - as evidence that most men with infected wives assumed that they were the origin of the disease and that both were already affected by it. Similarly only one-third of each sex told others, but the women did so mostly for support in refusing sex while the men were mostly complaining about their wives.

\section{How women believe they would react to infected male partners}

The research now turned back to what the reactions of all the respondents would be to their partners having a sexually transmitted disease. Their reactions are shown in Table 6, which should be interpreted in the sense that the respondents assume that they themselves are not infected with the disease.

Table 6.

Responses to the question 'If your husband/boyfriend becomes infected with a venereal disease, would you refuse to have sex with him?' and subsequent questions $(\mathbb{N}=601)$

Question

Response

Percentage of all responses

(1) (a) Would you refuse to have sex? (b) Why would you refuse?

(1) YES

(2) So as not to become infected

99

(2) [On being shown a condom]

(a) Do you know what this is?

(b) Have you and your partner ever used one?

(c). If your partner had a venereal disease, would you be willing to have sex

(3) YES

YES

YES

36 with him using a condom?

The table certainly shows a future determination by the respondents to protect themselves from infection. Actual experience, as we have seen, sometimes proves to be different, although even most of these women claim they would refuse sex next time. Many women may not realize that their husbands have a sexually transmitted disease or may not be able to convince him that 
that is what he is suffering from. Others may take the risk of infection rather than see the marriage deteriorate or other wives come into it.

What is most striking is that not even all those women who had experienced condoms would be prepared to employ them to continue having sex with partners who contracted a venereal disease. We explored this reluctance fully with the results set out in Table 7.

\section{Table 7}

Responses to the question 'Why wouldn't you be prepared to employ a condom and so continue having sex with a partner who had a venereal disease?' directed only to respondents who said they would not employ a condom to allow sexual relations to continue $(\mathrm{N}=216)$

Responses

Percentage distribution of responses

Major category

Subcategory
(1) Fear of infection (2) Fear of infection and
condoms

(3) Aversion to condoms

(4) Aversion to all contraceptives

(5) Aversion to partner (a) not convinced that condoms will guarantee against infection

(a) don't know enough about condoms to be able to make a decision about whether they are safe and whether they would prevent infection

(a) condoms are dangerous

(b) don't like sex with condoms

(a) abstinence is best

(b) cure won't take long and abstinence will suffice for this period

(a) would no longer feel like sex with him if he behaved so as to contract a venereal disease

(b) having sex with respondent would not be his main problem. He would have to get cured and sort himself out.
73

73

6

6

Major category
3

5

6

2

4

1

5

100

100

The fact that most respondents would not trust condoms to protect them from infection arises from a mistrust of these contraceptives. Many believe that they are too thin to give that type of protection. Everyone has stories, sometimes second-hand, perhaps apocryphal, of condoms breaking or coming off when being used. Perhaps some have been stored for too long, or are of poor quality, or are the wrong size.

There is still some residual fear that condoms themselves are more dangerous than anything else. Until recently, there was a widespread belief that condoms could slip off during use and end up lodged in the womb, causing injury and death. It is only their more widespread 
use that has, at least in urban areas, countered these fears. There is also a resistance, largely by Catholics and some members of the syncretic Africanist churches, to any form of contraception.

These findings must be seen against a background of very recent and quite steep increase in contraceptive use in Ado-Ekiti. This is partly a response to the economic structural adjustment program (SAP), but it also owes much to rising educational levels, the legitimation offered to contraception by the government's population policy, and the easy availability of contraception (Caldwell et al., 1992).

\section{To what extent do urban Ekiti women control their own bodies?}

The Yoruba women of Ado-Ekiti have certain advantages in controlling their sexuality. Traditionally they have been expected to play a major role, supported by their husbands and the husbands' relatives, in ensuring that sex does not take place for an appropriate lengthy period of time after the birth of each child, during pregnancy, menstruation and at older ages. There is a very clear concept of the woman being in charge of these decisions even if, and especially when, her husband shows weakness. This must, to some extent, flow over into other areas, at least when there is a moral dimension to the situation. It is recognized that there is a moral issue when the husband is drunk, and to some extent, at least in recent times, when he takes another wife without consulting the first. In addition, the Yoruba woman is to a large extent financially independent. She is a trader or has some other occupation: apart from a couple of students, only just over one per cent of the respondents in this study were solely dependent on their husbands for income. Admittedly, the Yoruba wife normally faces considerable cost in supporting herself and her children, and her husband normally helps with support costs, but she can usually walk out and stand alone if necessary. In addition her family of origin will welcome her back, and, if necessary, some relative will look after the children. She can often find another husband fairly quickly.

On the other hand, the society has high levels of polygyny and marital instability. Annoyed husbands can easily leave, to stay with their sisters or parents; or throw the wife out, or take another wife in. They can also go to other women friends. It is precisely these considerations that have been the major factor in forcing down the duration of postpartum sexual abstinence (Caldwell and Caldwell, 1981; P. Caldwell and J.C. Caldwell, 1987). Wives may be reluctant to break up marriages too easily. Furthermore, tradition has little to say about the wife's reaction to the husband's gonorrhoea; indeed it usually blamed her for giving it to him through disorders or imbalances in her menstrual or reproductive systems (Buckley, 1985:27ff.). Husbands may well take the high moral ground with regard to their right to sexual relations (some quoting the Bible), especially when there is some dispute about exactly what the disorder is and sometimes when the husband fails to disclose all he knows about it.

A Yoruba woman can clearly turn down her husband's advances on a single night. He may even feel some pride in this demonstration that he is too virile for her, and hardly knows his own strength. But there are great risks in continuing to refuse the husband's advances for any sustained period. Yet most persons recognize venereal disease as a reason for refusing sex to partners and the concept certainly now exists in the society. It may broaden in the HIV/AIDS era. 
One problem awaiting the HIV/AIDS era is the continuing deep suspicion of the condom as an STD prophylactic. How much greater is that suspicion likely to be for HIV. Yet the suspicion of the condom as an antinatal device is passing rapidly. The same may yet happen with regard to its prophylactic use. Much will depend on just how good the condoms are and whether there are genuine cases of their not preventing infection (or conception).

The major difference between STDs and HIV/AIDS is the latter's incurability, a situation which a growing proportion of the population of Ado-Ekiti now accepts because of the government's informational campaign (cf. Orubuloye, P. Caldwell and J.C. Caldwell, 1992). Women have been able to refuse sex in the case of STDs for the period of treatment. Indefinite refusal, as most anticipate in the case of HIV/AIDS, would be likely to result in the husband driving away the wife (except in the symptomatic stage where he would probably trade abstinence for care) or becoming threatening or violent, in which circumstance most wives would leave. A growing trust in condoms would probably mean that a number of marriages, but probably a minority, where the husband was seropositive, would remain intact. Where only the wife is seropositive in most cases she would probably be driven away.

What is clear from the research is that most Yoruba women have undisputed control of their sexuality when their partner suffers from STDs or AIDS. The refusal of sex may result in the breakup of a marriage but is unlikely to result in a continuing marriage dominated by violence or forced sex, or by pressure from their own relatives for the husband to be allowed his conjugal rights.

It appears probable that in an AIDS epidemic most Yoruba women with a seropositive husband will break off the marriage, refuse sex, or agree to it only with condoms - although the proportions adopting these choices cannot be predicted from the STD research. The exceptions will be those women, whether seropositive or seronegative, who have convinced themselves that they are probably already infected or those who do not believe the disease is incurable.

\section{Acknowledgements}

This research was funded by SAREC (the Swedish Agency for Research Cooperation with Developing Countries) and was developed from an earlier program funded by the Rockefeller Foundation. Resources have also been contributed by Ondo State University, Ado-Ekiti, Nigeria, and the Australian National University, Canberra. The authors wish to acknowledge the contribution in Nigeria of S. S. Oni, Jacob Oni, Mrs Fadeyibi and Mary Christopher, in Australia of Ben Amenuvegbe, Pat Moor, Wendy Cosford, Jenny Braid and Pat Goodall, and at Northwestern University, Evanston, of Caroline Bledsoe, Denise Miller, Calvin vander Leeuw and Leighton Peterson.

\section{References}

Ankrah, E.M., 1991, 'AIDS and the social side of health', Social Science and Medicine, 32,9:967-980.

Buckley, A.D., 1985, Yoruba Medicine, Clarendon, Oxford.

Caldwell, J.C. and Caldwell, P., 1977, 'The role of marital sexual abstinence in determining fertility: a study of the Yoruba in Nigeria', Population Studies, 31,2:193-217.

Caldwell, J.C. and Caldwell, P., 1981, 'Cause and sequence in the reduction of post-natal abstinence in Ibadan City, Nigeria', in Page and Lesthaeghe, 1981. 
Caldwell, J.C. and Caldwell, P., 1987, 'The cultural context of high fertility in Sub-Saharan Africa', Population and Development Review, 13,3:409-437.

Caldwell, J.C., Orubuloye, I.O. and Caldwell, P., 1991, 'The destabilization of the traditional Yoruba sexual system', Population and Development Review, 17,2:229-262.

Caldwell, J.C., Orubuloye, I.O. and Caldwell, P., 1992, 'Africa's new kind of fertility transition', Seminar Paper, Demography Program, Australian National University, Canberra.

Caldwell, P. and Caldwell, J.C., 1981, 'The function of child-spacing in traditional societies and the direction of change', in Page and Lesthaeghe, 1981.

Caldwell, P., and Caldwell, J.C., 1987, 'Fertility control as innovation: a report on in-depth interviews in Ibadan, Nigeria', in J.A. Ebigbola and E. van de Walle, eds., The Cultural Roots of African Fertility Regime, University of Pennsylvania, Philadelphia and Obafemi Awolowo University, Ile-Ife.

Cleland, J.G., Carael, M., Deheneffe, J.C. and Ferry, B., 1991, 'Behaviour in the face of risk: the case of AIDS in Africa', Paper presented at Annual conference of the British Society of Population Studies, on Historial Epidemiology and the Health Transition, University of Southampton, Southampton, U.K., 11-13 September.

Hopkins, A.G., 1969, 'A report on the Yoruba, 1910', Journal of the Historical Society of Nigeria, 5,1:67-100.

Irwin, K., Bertrand, J., Mibandumba, N., Mbuyi, K. et al., 1991, 'Knowledge, attitudes and beliefs about HIV infection and AIDS among healthy factory workers and their wives, Kinshasa, Zaire', Social Science and Medicine, 32,8:917-930.

McGrath, J.W., Rwabukwali, C.B., Schumann, D.A., Pearson, J., Nakayiwa, S., Namande, B., Nakyobe, L. and Mukassa, R. n.d., 'Anthropology and AIDS: sexual risk behavior among Baganda women', Department of Anthropology, Case Western Reserve University, Cleveland, Ohio, mimeograph.

Orubuloye, I.O., Caldwell, J.C. and Caldwell, P., 1991, 'Sexual networking in the Ekiti District of Nigeria', Studies in Family Planning, 22,2:61-73.

Orubuloye, I.O., Caldwell, J.C. and Caldwell, P., 1992, 'Focus and diffusion: sexual networking and identifying partners' partners', Health Transition Centre Working Paper No. 11, Australian National University, Canberra.

Orubuloye, I.O., Caldwell, P. and Caldwell, J.C., 1992, 'The role of high-risk occupations in the spread of AIDS: truck drivers and itinerant market women in Nigeria', Health Transition Centre Working Paper No. 10, Australian National University, Canberra.

Osoba, A.O., 1981, 'Sexually transmitted diseases in tropical Africa: a review of the present situation', British Journal of Venereal Diseases, 57,2:89-94.

Page, H.J. and Lesthaeghe, R.J. (eds), 1981, Child-spacing in Tropical Africa: Traditions and Change, Academic Press, London. 


\section{HEALTH TRANSITION CENTRE PUBLICATIONS}

\section{WORKING PAPERS}

1. Larson, Ann (1989)

Social context of human immunodeficiency virus transmission in Africa: historical and cultural bases of east and central African sexual relations

Review of Infectious Diseases, II, 5:716-731

2 Caldwell, John C., Pat Caldwell and Pat Quiggin (1989)

The social context of AIDS in sub-Saharan Africa

Population and Development Review, 15, 2:185-234

3. Orubuloye, I.O., John C. Cald well and Pat Caldwell (1991)

Sexual networking in the Ekiti District of Nigeria

Studies in Family Planning 22,2:61-73

4. Caldwell, John C., I.O. Orubuloye and Pat Caldwell (1991)

The destabilization of the traditional Yoruba sexual system

Population and Development Review, 17,2:229-262

5. Caldwell, John C., Pat Caldwell and I.O. Orubuloye (1990)

The family and sexual networking in sub-Saharan Africa:

historic regional differences and present day implications.

6. Caldwell, Pat (1990)

Research Priorities: Behavioural Research

(with an Annexe on needed research with

priority suggestions)

6a. Caldwell, Pat (1990)

Annexe to Research Priorities: Behavioural Research

7. Caldwell, Pat and John C. Caldwell (1990)

Gender implications for survival in South Asia

8. Orubuloye, I.O., John C. Caldwell and Pat Cald well (1991)

The impact of family and budget structure on health treatment in Nigeria

9. Caldwell, John C., I.O. Orubuloye and Pat Caldwell (1991)

Underreaction to AIDS in Sub-Saharan Africa

10. Orubuloye, I.O., Pat Caldwell and John C. Caldwell (1992)

The role of high-risk occupations in the spread of AIDS: truckdrivers and itinerant market women in Nigeria

11. Orubuloye, I.O., John C. Cald well and Pat Caldwell (1992)

Diffusion and focus in sexual networking: identifying partners and partners' partners 
12. Orubuloye, I.O., Pat Caldwell and John C. Caldwell (1992)

African women's control over their sexuality in an era of AIDS

\section{HEALTH TRANSITION SERIES}

1. Caldwell, John C. and Gigi Santow (eds) (1989).

Selected Readings in the Cultural, Social and Behavioural Determinants of Health. Canberra: Health Transition Centre, Australian National University. xix $+305 p p$

2 Cald well, John C., Sally Findley, Pat Caldwell, Gigi Santow,

Wendy Cosford, Jennifer Braid and Daphne Broers-Freeman (eds) (1990), What we know about Health Transition: the cultural, social and behavioural determinants of health, Canberra: Health Transition Centre, Australian National University xix + 933pp..

3. Cleland, John and Allan G. Hill (eds) (1991)

The Health Transition: Methods and Measures, Canberra: Health Transition Centre, Australian National University.

\section{JOURNAL}

Health Transition Review Vol. 1 No. 1 April, 1991

Health Transition Review Vol. 1 No. 2 October, 1991 